\title{
The family as basis of social order: insights from the Yoruba traditional culture
}

\author{
Shitta-Bey Olanrewaju Abdul \\ Department of Philosophy, Faculty of Arts, Lagos State University, Lagos, Nigeria \\ E-mail address: tilewa02@yahoo.co.uk
}

\begin{abstract}
Western form of civilization, which has afforded every nook and cranny of the world the opportunity to witness advancements in various facets of life, is accompanied by orientations which destroy traditional efforts - like the family systems - that engendered peace in various societies; and thus, with high-tech advancements today, the quest for social order is more pronounced than ever before. This paper interrogates the Yoruba traditional culture with a view to account for the role of the family system in achieving social order. Thus, it proceeds with a critical analysis of the idea of the family and the family system in Yoruba traditional society. It examines the notion of social order for the purpose of invoking a clear and distinct working understanding of the term. In order to achieve the set objectives identified above, this paper employs the trio methodology of translation, interpretation, and critical analysis. The translation and interpretation methods are employed as viable approaches to interrogate the oral texts with which we shall partly be dealing with; and the critical analysis method is adopted to achieve the twin goals of clarity and simplification of both the oral and the written literatures at our disposal. In the light of the above, this paper invigorates a discourse on the Yoruba traditional culture, and specifically unveils the importance of the family system within the culture in achieving social order. It seeks to bring into focus the impacts of the family in the society within the ambit of the Yoruba philosophical traditions, and how this matters in engendering social order.
\end{abstract}

Keywords: social order; culture; Yoruba; Ebi; Olori-Ebi

\section{INTRODUCTION}

The importance of order in the existence of an individual and the society cannot be ignored. For instance, an individual's biological system needs to be in order to function properly and adequately, otherwise there would be biological dysfunction or disorder. In its application to the society, it means that it is required to keep the society intact, functional, and safe for the purpose of attaining progress in all ramifications.

Thus, the inevitability of order in any society cannot be undermined; its existence remains significant in any society that thrives to achieve development in any sphere of life. In fact, it is the drive to ensure the existence of order that modern states exist; however, this primary responsibility to maintain order by modern states - with their paraphernalia of government institutions and structures - appears difficult to achieve going by contemporary reality of crises occurring in every nooks and corners of the world. 
The belief in the idea that different situations (as we have modern versus traditional societies) demand different conditions as necessary for the existence and persistence of social order has led some modern states, for instance, to apply government institutions of naked forces like the police and the army or legal instruments to enforce social order within their enclaves. As reality of today as shown, however, modern states' apparatus of any kind have failed in ensuring sustainable and endurable social order in many of these states; and hence, the current conflicts as witnessed in many today's societies.

As an alternative, this paper interrogates the Yoruba traditional culture with a view to explicate the structure and practice of the family system that is indigenous to it; this is in order to demonstrate that this indigenous family system as structured and practiced in Yoruba culture engenders sustainable and endurable social order. That is, the Yoruba traditional family system primarily promotes the existence and persistence of social order; and this can be replicated in contemporary societies in order to address the current social disorders in many parts of the world.

To provide an adequate discourse on the stated supposition, this paper is structured into five sections viz-a-viz this 'Introduction' - which introduces the problem, content, and objective that the paper contends with; 'The Family System in Yoruba Traditional Culture' where we discuss the structure and organization of the family system that is indigenous to the Yoruba culture; 'Social Order: Astute Definition and Conditions Necessary for Its Existence' - that examines the meaning and the conditions necessary for the existence of social order; 'On Family System Mechanism that Engenders Social Order in Classical Yoruba Culture' which explores the social importance of the Yoruba family system, especially its functionality to promote social order; and lastly, 'Conclusion' - where we summarize and make general remarks about the entire discourse.

\section{THE FAMILY SYSTEM IN YORUBA TRADITIONAL CULTURE}

The task to classify the family system that is indigenous to the Yoruba culture using Western category is a difficult one. In fact, it is certain that this system cannot be classified as any one of the followings (Elliot and Gray, 2010: 6):

1. A nuclear family - a two generation family consisting of a father and mother and their children or a single, possibly widowed, parent and his/her children.

2. A stem family - a three-generation family consisting of a father and mother, married children, their spouses and their children.

3. A lineal family - the families of several married siblings who are linked to their common family of orientation, that is, to the family of their parents. Such a family dissolves with the death of the parents and may become a laterally extended family, where links are maintained, or split into individual nuclear families. They do not necessarily live together.

4. An extended or jointly family - three or more generations live together with both vertical and lateral extensions, with a single line of authority, either patrineal or matrineal.

5. A compound family - when two families combine after divorce.

From all indications, it appears easy to discern where and how to place the family system that is traditional to the Yoruba culture following the classification above; but account of the Yoruba traditional family system in subsequent paragraphs will prove otherwise. In 
other words, the account to be given in subsequent paragraphs of this section would demonstrate that the family system in classical Yoruba culture is difficult to classify into any of the Western categories of family identified above.

In classical Yoruba culture, it is common knowledge that a family household occupies a large compound; and in this compound, one would find three or more generations from a particular genealogy and/or other families of different genealogies living together as one indivisible family. It is in this line that Elliot and Gray report that

\footnotetext{
The family is not necessarily, or even essentially, a biological unit. It is a social construct. The 'myth' of biological relations has been used in arguments about property and inheritance but has little relation to the way people operate in terms of families (2010: 6)
}

In Yoruba parlance, Ebi is the appropriate term for family and it is the basic unit of the society; Atanda corroborated this submission when he writes that "the Yoruba, in the course of their development, evolved a social organization in which the lineage, ebi or idile is basic" (1996: 18).

In this connection, two distinct but intertwined meanings of Ebi are palpable. On the one hand is what we can call the denotative meaning; this means that the term describes a typical family household that is indigenous to the Yoruba culture, Ebi in this sense means members of a family residing in one household. This is why each individual is identified by the public not with any of his/her direct parents, but with the household that he/she resides.

On the other hand is what we can call the connotative meaning of the term. In this respect, it means that the term connotes family bonds beyond what obtains either in a nuclear or extended family, that is, Ebi means that an individual has family connections with so many other individuals outside the immediate household that he/she resides, in other words, the term suggests that one's family goes beyond one's nuclear and extended families.

In its denotative sense, Ebi as a family household occupies a large compound popularly called Agbo Ile (conglomerate of houses) where each individual member of the household possesses an apartment of his/her own with or without a nuclear or extended family. For clarity, Fadipe adequately illustrated this explication when he writes that

\footnotetext{
The prevalent form of human dwelling-place in Yorubaland is a collection of apartments for individual families. These apartments together are known as the compound, or to the Yoruba as agbo ile (lit., a flock of houses). They consist of two or more rooms for each family - polygynous or monogamous - and adjoin each other, with a common wall between adjacent apartments. The whole collection forms a square enclosing an open space in the middle. A verandah, which opens on to the quadrangle, runs right round the compound and, unlike the rooms behind it, it is not divided by any partition so as to enable inmates to walk from one end of the compound to the other under cover (1970: 97-98).
}

This is the outlook of a typical Yoruba traditional family household; and this is the very reason we have said that a family in the Yoruba traditional society is a household consisting of three or more generations from the same genealogy and/or other families of different genealogies living together as one. This submission sounds as one that can pass as an extended family, but it is not. For instance, unlike the extended family where a single line of authority exist - patrineal or matrineal, the Yoruba family household has no single line of authority; that is, the line of authority in a typical Yoruba traditional family system can be patrineal or matrineal. 
In the Agbo Ile, there are families of different lineages that live together as one in commensality. Some of these families of different lineages may have relationships with the household through marriage, adoption, and other linkages created by human or natural factors - for example, displacement resulting from either war or natural disaster.

This is why, for instance, if a particular individual marries from a particular household, the two households now become one Ebi; in this sense, it means that Ebi also evolves from marriage. This is the picture painted by Fadipe when he posits that

All the members of a compound other than those women who have been admitted into it by marriage are related to one another on the father's side ..., however, the women who have been married into the compound at each generation are also members of the ebi household (1970: 99).

and that

... slaves who, on redeeming themselves, became adopted members of the family which they previously served (1970: 99-100).

As a matter of importance, one significant and fundamental notion that is worthy of explication in any discourse on the Yoruba traditional family system is the idea of Olori Ebi (Head of the Family) or what Fadipe calls Baale (Father of the House); and according to him, "the eldest male is, other things being equal, the head of the compound" (1970: 99). By other things being equal, it shows that some situations arise where the eldest female becomes the head of the household.

It is important to state that it is safe, for us in this paper, to identify with the term 'Olori $E b i$ ' rather than Baale - for Baale signifies the masculine gender, while Olori Ebi is genderneutral. By this, it means that in Yoruba traditional society, the eldest male or female (rather than the eldest male alone; but often times it is the eldest male) serves as the head of the household. Whether male or female, most important for this paper is the establishment that the Ebi (family household) must have an Olori Ebi (head of the family).

The Olori Ebi, functionally, exercises authority over each and every members of the $E b i$; as a matter of social necessity, s/he has the primary responsibility to regulate, manage, and administer all affairs in, and relating to, the Ebi. It is in this connection that Fadipe writes that

It is the duty of the baale (the Olori Ebi) to preserve peace and order within his compound, a duty he probably owes, in the first place, to the members of the compound, and only secondarily to the large community... It is his duty to see that the members of his compound are of mutual benefit to each other and interact with a minimum of friction (1970: 106)

In sum, the family system that is traditional to the Yoruba culture is called Ebi and it is the basic unit of the society. The Ebi, it is noted, consists of not just generations of a particular genealogy but also families from different genealogies whose links can be through marriage or adoption or other linkages arising from human or natural factors. We also noted that each Ebi has an Olori Ebi, who exercises authority over members of the household.

From the foregoing, it means that each existing individual in indigenous Yoruba setting belongs to an Ebi and cannot exist in isolation; also, the individual can only be reckoned with in the larger society only on the basis of his/her family household. 


\title{
3. SOCIAL ORDER: ASTUTE DEFINITION AND CONDITIONS NECESSARY FOR ITS EXISTENCE
}

The desirability of order in both individual and social existence cannot be overemphasized. We have said both individual and social existence because each person is both an individual and a social being; that is, while each one is an autonomous being, one is also a social being. In other words, each person must exist as an individual as well as co-exist with other individuals. In a very clear articulation, Gripaldo corroborated this supposition when he notes that

\begin{abstract}
The person is not an island unto himself. For his/her survival and belonging needs, $\mathrm{s} /$ he is not simply a mere member of a socio-cultural group - a mere individual - but $\mathrm{s}$ /he cooperates with the members of that group. In short, $\mathrm{s} /$ he is also a social being (Gripaldo, 2003: 1).
\end{abstract}

In fact, as a general rule that applies to all existing humans, Gyekye explains that no individual can live in isolation and be self-sufficient; hence, the essentiality of social relations defines each individual as a social being. In his own words, he submits thus

\footnotetext{
... the human person is ... by nature a social being from the outset and therefore, cannot and should not live in isolation from other persons. Thus, social relationships are essential for every human person, for no one is selfsufficient and therefore no one can, in isolation, function adequately in the social context (Gyekye, 1996: 36).
}

It is in the light of the above that we have stated that the desirability of order in both individual and social existence cannot be over-emphasized. By this submission, couple with the explanation above, it means that the term 'order' prefixed with the word 'social' to coin 'social order' captures a sense of order that exist in the social world. Thus, the term 'social order' refers to the existing order in the society which encompasses conglomerate of existing individuals. It is important to state that the term (that is social order), though appears simple and easy to understand, is heavily loaded with technical meanings in the field of academic disciplines.

What then is social order? Like any other concept, it is characterized by as many meanings as there are many experts that have employed the term in one way or the other. According to one compendium of knowledge, the word 'social order' is defined as "the ranking in which a group of animals establishes itself with the most dominant one in the number one position and the most retiring one in the last position.

The order is maintained unless new animals are introduced" (Saunders Comprehensive Veterinary Dictionary: 2007). This definition appears too wide for our usage here because it refers to animals of any kind in general, however, it is important to take note of the implicit idea that social order is about the maintenance of an organization for an unspecified period of time.

In a medical dictionary, the notion 'social order' is defined as "the manner in which society is organized and the rules and standard required to maintain that organization" (Mosby's Medical Dictionary: 2009). Unlike the first definition, this definition appears better for being concerned with the society, but a society can be a society of animals, human beings, and so on; thus, it also appears to be too wide rather than narrow on its surface appearance. 
However, we should also take note of the idea of maintenance of an organization and the rules and regulations required to maintain the organization as important indices in the matter of social order.

In another sense, the term is defined as "the concept of a society structure in its norms of relations expectation and plausible outcomes which might lead to peace and domestic tranquility", meaning that it "refers to a set of inter-linked and inter-dependent social structures, social institutions, and social practices which play a significant role in maintaining a particular way of life or society" (Pereira, 2011: 47).

Without any form of ambiguity, this definition like the ones considered above is also broad, but it is useful in that it seems to incorporate important components; these incorporated components include 'society structures', 'norms of relations', 'expectations', 'outcomes', and so on; however, there is nothing in the definition to indicate that the human society is being referred to and to show the significance of human persons as constituting individuals as well as a collectivity.

From the above, it is easily recognizable that we can have as many definitions of social order as many scholars that have touched on the subject. However, for the purpose of this paper, we are concerned with the normative use of the term, that is, in a prudential sense. Thus, the definition of social order as employed in this study is 'the conditions responsible and necessary for the existence and persistence of peace in the social world of human persons'. It is important to state that the emphasis here is on the conditions responsible and necessary for the existence and persistence of peaceful cohabitation in human society.

In dealing with the conditions that are necessary and responsible for social order in human society, it is most appropriate to turn to the human persons that constitute the society since they engage in social practices, form social institutions, regulate social rules and standards, and establish social structures. It is in this light that one scholar submits that

For social order to arise and be maintained, two separate problems must be overcome. People must be able to coordinate their actions and they must cooperate to attain common goals (Hechter \& Horne, $2009: 1$ ).

Most obvious, the conditions necessary and responsible for social order as articulated in the submission above are coordination and cooperation; and these cannot be executed without the human persons. Therefore, if one is interested in the discourse on the existence and persistence of social order (like we do in this paper), then one must seek to know how the human persons coordinate and cooperate among themselves. This interest leads us to the core focus of this paper - where we considered the family system as one of the fundamental ways through which coordination and cooperation are executed among people in classical Yoruba culture.

\section{FAMILY SYSTEM MECHANISM AND SOCIAL ORDER IN CLASSICAL YORUBA CULTURE}

It is important to restate some important remarks that have been made about the family system that is indigenous to the Yoruba culture, and this is to simplify the task of elucidating the means by which the family system in Yoruba culture engenders social order. It should be recalled that we demonstrated the mandatory association or identification of each individual with a particular household or Ebi rather than as an isolated individual. This is made possible because 


\begin{abstract}
The process of socialization begins from birth where the mother consistently communicates with the baby by tracing the family tree from the beginning, reminding him/her of the nobility of his/her birth and the uniqueness of the family. In fact, co-wives are on hand to tease the growing child, chanting the family praise-names ... All these raise the consciousness of the child as a member of a family and he/she begins to internalize its norms (Gbadegesin, 1991: 62).
\end{abstract}

In this connection, each individual has the responsibility to protect the name and image of the Ebi. The inculcation of values and codes of conduct that project the good name of the $E b i$ in the larger society into the psyche of each member is a fundamental mechanism that engenders social order. In other words, the socialization process which each individual in the larger society is made to go through within the family system promotes the existence and persistence of peace in the society. Gbadegesin elucidates clearly

\begin{abstract}
In this kind of environment, growing children are able to see themselves as a part of a household and not as atoms. They see their intrinsic relation to others and see the interdependent existence of their lives with others ... Not that the community forces itself on an unyielding individual; rather the individual, through socialization and the love and concern which the household and community have extended to him/her cannot now see himself or herself as anything apart from his/her community. Interest in his/her success is shown by members of the extended family who regard him/her as their "blood" and the community are also able to trace their origin to a common even if mythical ancestor. There is therefore a feeling of solidarity among its members and this is neither forced nor solicited. It develops naturally as a result of the experience of love and concern which the growing child has been exposed to (ibid: 63).
\end{abstract}

The observation above adequately demonstrates the reason social order is not threatened or challenged by the action of any individual in the society, for each one carries with himself/herself the emblem of the $E b i$; and thus, he/she is expected not to bring shame to the Ebi by performing shameful acts in public domains. In the same vein, good conducts that promote and protect the well being of the society at large by any individual are attributed not just to the individual but fundamentally to the Ebi, meaning that an individual is not expected to bring shame to the Ebi, but he/she is expected to bring commendation to the Ebi. In fact, according to Fadipe,

\footnotetext{
A man derives his position in the wider political community in which he lives only through his membership in his compound ... His rights and privileges accrue to him only through the head of the compound. His duties also to the wider society are duties which devolve upon the compound (1970: 106)
}

In this regard, anyone that demands to know an individual who has acted in a good way or otherwise would demand to know by asking the question Omo Idile wo ni? (which translates as The fellow is of which household?). Therefore, the Ebi is not just a cultural signification but also an executor of social rules, values, codes, and norms among its members through the Olori Ebi. Most importantly, therefore, 
Within the larger society, each Ebi ensures that the adequate coordination and cooperation of the Ebi for the benefits of each individual, the household, and the society at large is not wanting. Coordination, for instance, is observed in the form of punishing the young ones by the elderly in the household regardless of whether the elderly one is the biological parent or not; that is, the power or authority to punish younger members of the Ebi when they misbehave lies with any member of the Ebi that is older that the young one in question. Gbadegesin reiterated this point very clearly when he submits that

\begin{abstract}
Inside each apartment, the children of co-wives and other elderly members play together and are overseen by the elders. A child who misbehaves is corrected immediately and may be punished by any of the elders ... Then in the larger compound, all the children play together and, again, any of them may be punished by any older member of the household for misbehaving (1991: 63)
\end{abstract}

The reinforcement of cooperation within the Ebi, which is also replicated in the larger society, takes different manners. For examples, there is the institutionalized Owe - a kind of collective help involving in-laws, relatives, friends, and neighbours of a productive nature, which an individual commissions and relies on in certain circumstances like the building of a house or the rebuilding or reroofing of one, and clearing of land, bush, or forest growth (see Fadipe, 1970: 150); there is the Aso Ebi - which literally means the cloth of a kinship group or a family and serves as a means of identification of groups affording members of the groups the opportunity for reinforcement of one another with sympathies to meet the trials and tribulation and pleasures of life and integrating the group (see Sofola, 1973:125-126); and so on. Cooperation is also exhibited among women related to the family through marriage; this is adequately explicated in the submission that

\footnotetext{
Wives of the family (co-wives, wives of brothers, wives of cousins, etc) know that they are expected to cooperate in raising their children as full members of the family. They are free to borrow household items from one another, they feel free to baby-sit for one another, they advice one another and settle any dispute between themselves and their children ... And where there is a misunderstanding among the co-wives that cannot be settled among themselves, the elderly male or female members intervene, or if they do not succeed, the matter is taken to the head of the compound (Gbadegesin, 1991: 63-65)
}

In this regard, since the society is a collection of all Ebi (being smallest units of the social system) rather the collection of individuals, it means that the congregation of all Ebi serves as designer of social values and customs that promote and protect the wellbeing of both individuals and the society; therefore, as designer of social standards, members of each Ebi must imbibe all social rules as dictated within the Ebi.

It is in line with this understanding that Atanda remarks thus

It is instructive to point out the indisputable fact that no Yoruba man, I mean the one born and bred in the society, would dare do anything against alajobi (family or lineage bond), knowing and believing in the grave consequences that might follow. That concept (that is, the concept of Ebi), has gone a long way in promoting social harmony and stability (1996: 19) 
Among the Yoruba, thus, if an individual's action threaten the peace of the society, it is the image of the Ebi that suffers. As a result, to project the image of the Ebi in good light in the larger society, the household ensures that members are given adequate trainings, often informally, that reflect a respectable $E b i$ in the conduct of each individual. As an embodiment of individuals carrying the signposts of one Ebi or the other, the society at large experiences endurable peace and stability, with insignificant or no conflict, which enhances the progress and development of the society. Gbadegesin sheds more light on this in his submission that

\begin{abstract}
The process of socialization that begins in the family apartment and the household compound finally gets into the larger community where the child is further exposed to the virtues of communal life. Here children of the community are exposed to the display of selfless efforts by others to uplift the community. They have a first-hand experience of how adults are contributing to the welfare of children, how women and men work on the farms and how the warriors risk their lives to save the community. Building on the initial exposure in the family compound, therefore, they now see themselves as one of those who should carry the banner and, having been prepared for the task, they, severally and collectively, cannot but shun individualism that promotes self-centeredness (Gbadegesin, 1991: 63).
\end{abstract}

In view of the above, it is important to note that peaceful coexistence or social peace is not engendered with the instruments of institutionalized and legalized naked forces like the police or the army, rather it evolves from (and revolves around) the family system where it is significant that each member of the society is an ambassador of an Ebi; therefore, the only driving force towards exhibiting positive conducts which advance social order and rejecting negative conducts that promote social disorderliness is the consciousness to promote and protect the good name of the Ebi.

\title{
5. CONCLUSIONS
}

In sum, Ebi is the family system that is indigenous to the Yoruba culture, and it is the smallest unit of the society. Although, modernization (or should we say Europeanization) has eroded this family system away from the major cities in Yoruba land, but it still exists largely in the rural areas of the land where one can have direct empirical knowledge of its social significance. However, it is important to recognize that most people of Yoruba extraction that dwell in the cities within and outside Yoruba land are still involved in important ways on matters of Ebi either in its denotative or connotative senses, which goes to show the strong influence of the culture on members of the group in contemporary period in the face of modernization.

This summation leaves us with one distinct and important conclusion, and this is the view that the Yoruba traditional family system plays significant roles in all spheres of the life of the society; it is on this note that Atanda argues that

The lineage $i s$ an important and indispensable fabric of society and the focus and centre of each descent group within the society. It is a fabric which remain resilient even in the face of stresses of any kind. It plays vital roles in the social, political, economic, religious, judicial and intellectual aspects of life (Atanda, 1996: 18) 
Let us recall that the sine qua non for the existence and persistence of social order are coordination and cooperation of people that makes up the society; these conditions are adequately present in the organization of the family system in Yoruba traditional culture as demonstrated above. What is left to be said is that contemporary societies with arrays of conflicts and disorderliness can borrow a leaf or more from this social organization, to address their present situations.

It is important to note that there are views which suggest and indicate that the social arrangement or part of the social arrangement espoused in this paper - which is the family system - is common among Africans and not peculiar to the Yoruba traditional society; for instance, this is indicated in the submission that

\begin{abstract}
Of the measures that are calculated to insure the solidarity of two lineages, the initial one is the marriage ceremonies. In most African societies, the family institution has the characteristic of solidifying the relationship between two distinct families or lineages, rather than between two individuals only. Marriage in Africa is a union of the lineages for the purpose of procreation, companionship, assistantship etc. and the continuity to that relationship (Sofola, 1873: 5-6).
\end{abstract}

How far this is true is left for further research on the subject-matter in other cultures indigenous to the continent. What is important for now is to show, as we have done, that traditional family system in Yoruba culture served as the basis of social order; and that this can be re-invoked as a remedy to address the current disorderliness in our world today.

\title{
References
}

[1] Atanda, J.A. 1996. "The Yoruba People: Their Origin, Culture and Civilization" in The Yoruba: History, Culture and Languages (J.F Odunjo Memorial Lectures Series 5) edited by Olatunji, O.O. Ibadan: Ibadan University Press (Publishing House), Pp 3-34.

[2] Elliot, S. and Gray, A. 2010. Family Structures: A Report for the New Zealand Immigration Service. Te Ratonga Menene: New Zealand Immigration Service.

[3] Fadipe, N.A 1970. The Sociology of the Yoruba. ed. with intro. by Okediji, F.O. \& Okediji, O.O. Ibadan: University Press.

[4] Gbadegesin, S. 1991. African Philosophy: Traditional Yoruba Philosophy and Contemporary African Realities. New York: Peter Lang.

[5] Gripaldo, R.M. 2003. "The Person As Individual and Social Being”. A paper published in the Proceedings of the International Conference on The Dialogue of Cultural Traditions: A Global Perspective. Istanbu, 8-9 August.

[6] Gyekye, K. 1996. African Cultural Values: An Introduction. Philadelphia, Pa/Accra: Sankofa Publishing Company.

[7] Hecter, M and Horne, C. (eds.) 2009. Theories of Social Order: A Reader, $2^{\text {nd }}$ edition. Stanford, California: Stanford University Press. 
[8] Mosby's Medical Dictionary, $8^{\text {th }}$ edition, 2009.

[9] Pereira, S. 2011. "Social Control, Social Order, Social Mobility and Social Change" in Saunders Comprehensive Veterinary Dictionary, $3^{\text {rd }}$ edition, 2007.

[10] Sofola, J.A. 1973. African Culture and African Personality: What makes an African Person African. Ibadan: African Resources Publishers Co.

( Received 25 February 2014; accepted 02 March 2014 ) 